NOTICE: this is the author's version of a work that was accepted for publication in Journal of Petroleum Science and Engineering. Changes resulting from the publishing process, such as peer review, editing, corrections, structural formatting, and other quality control mechanisms may not be reflected in this document. Changes may have been made to this work since it was submitted for publication. A definitive version was subsequently published in Journal of Petroleum Science and Engineering, Vol. 55, issue 3/4, 2007, http://dx.doi.org/ 10.1016/j.petrol.2006.08.008 


\title{
Prediction of shear wave velocity from petrophysical data utilizing intelligent systems: An example from a sandstone reservoir of Carnarvon Basin, Australia
}

\author{
Rezaee, R. ${ }^{a}$; Kadkhodaie Ilkhchi, A. ${ }^{b *}$ and Barabadi, $\mathrm{A}^{c}$ \\ School of Geology, University of Tehran, Iran
}

\begin{abstract}
Shear wave velocity associated with compressional wave velocity can provide the accurate data for geophysical study of a reservoir. These so called petroacoustic studies have important role in reservoir characterization such as lithology determination, identifying pore fluid type, and geophysical interpretation.

In this study, a fuzzy logic, a neuro-fuzzy and an artificial neural network approaches were used as intelligent tools to predict shear wave velocity from petrophysical data. The petrophysical data of two wells were used for constructing intelligent models in a sandstone reservoir of Carnarvon Basin, NW Shelf of Australia. A third well of the field was used to evaluate the reliability of the models.

The results show that intelligent models have been successful for prediction of shear wave velocity from conventional well log data.
\end{abstract}

Keywords: Shear wave velocity, fuzzy logic, neuro- fuzzy, artificial neural network, petrophysical data, Carnarvon Basin, Australia

\footnotetext{
a- Fax: +982166491623

Email: mrezaee@,khayam.ut.ac.ir and mrezaee@gcn.edu.ou

Present Address: School of Geology and Geophysics, University of Oklahoma, USA

$b^{*}$ - Corresponding author: Fax: +98 2188771243.

Email: akadkhoda@,khayam.ut.a.ir

c- Fax: +98 2188771243

Email: abarabadi@toosgeo.com
} 


\section{Introduction}

Reservoir characterization is a prerequisite study for oil and gas field development. Shear velocity is as an important parameter for reservoir characterization studies. Due to several reasons such as high costs of measuring and lack of shear wave data in old wells, some intervals of reservoirs may not have those data. Therefore, it will be useful to predict shear velocity from well log data without direct measuring. For this purpose, several studies have been carried out up to now. Pickett (1963), Krief et al., (1990), Greenberg and Castagna (1992), Castagna et al., (1993), Bastos et al., (1998), Domenico (1984), Han (1986), Gassmann (1951) and Murphy et al., (1993) have developed empirical relationships for the prediction of shear velocity. In recent years, intelligent systems have been used for modeling and prediction in many petroleum related sciences. In this study, intelligent systems including fuzzy logic (FL), neuro-fuzzy (NF) and artificial neural network (ANN) have been used for prediction of shear velocity from well $\log$ data in a sandstone reservoir of Carnarvon Basin, NW Shelf, Australia.

\section{Methods used}

\subsection{Fuzzy logic}

The basic concept of fuzzy logic or more generally fuzzy set theory was first introduced by Zadeh in 1965 . Unlike crisp logic (CL), which a value may or may not belong to one class, fuzzy sets allow partial membership. The membership or non-membership of an element $\mathrm{x}$ in crisp set $C$ is described by a characteristic function $\mu_{C}(\mathrm{x})$, where:

$\mu_{C}(\mathrm{x})= \begin{cases}1 & \text { if } \mathrm{x} \in C \\ 0 & \text { otherwise }\end{cases}$

Fuzzy set theory extends this concept by defining partial membership which can take values ranging from 0 to 1 :

$$
\mu_{\mathrm{F}}(\mathrm{x}): \mathrm{X} \longrightarrow[0,1]
$$


Where $\mathrm{X}$ refers to the universal set defined in specific problem and $F$ is a fuzzy set (Yagar and Zadeh, 1992). Fig. 1 shows the membership functions for a crisp set $C$ and fuzzy set $F$.

\subsubsection{Fuzzy inference system (FIS)}

Fuzzy inference is the process of formulating from a given input to an output using fuzzy logic (Matlab user's guide, 2001). There are two types of fuzzy inference systems: Mamdani (1975) and Takagi-Sugeno (1985). Mamdani's method attempts to control a system by synthesizing a set of linguistic control rules obtained from experienced human operators. The Takagi-Sugeno method is similar to the Mamdani FIS. The main difference between them is that the output membership functions are only constant or linear for Sugeno-type FIS (Matlab user's guide, 2001). In the TakagiSugeno FIS, membership functions are defined by a clustering process. Assuming a smaller cluster radius will usually yield many small clusters and specifying a large cluster radius yield a few large clusters in the data (Chiu, 1994). Each of these clusters referred to a membership function (MF). These MFs will generate a set of fuzzy if-then rule for formulating inputs to output. A simple fuzzy if-then rule is described as below:

If $\mathrm{Vp}$ is high then $\mathrm{Vs}$ is high

This rule is composed of two parts: Antecedent (if part) and consequent (then part). If there are multiple parts to the antecedent, fuzzy logic operators make the relationship between them. The most common fuzzy operators are "and", "or" and "not". For example in the following rule "and" operator has been used:

If $\mathrm{Vp}$ is low and NPHI is high then $\mathrm{Vs}$ is low

Fig. 2 shows a comparison between these operators in FL and CL approaches. The closer a given input is to the "if" part of the rule; the more the "then" part will be influenced. Finally fuzzy system adds up all of the "then" parts and uses a defuzzification method to give the final output (Kosko, 1991). 


\subsubsection{Why to use fuzzy sets?}

Geosciences are not completely precise and most of the time, are associated with uncertainty. Regarding to imprecise nature of fuzzy sets it will be better to use fuzzy reasoning for solving problems which accompany vagueness and imperfection. Here, we show a simple petrophysical example to clarify the problem:

The cutoff value of porosity for oil reservoirs generally is about $5 \%$. It means if an interval has more than $5 \%$ porosity, it will be considered as net pay. Fig. 3 shows the membership functions for porosity cutoff in CL and FL approaches respectively. According to CL approach (Fig. 3a); the porosity value of $4 \%$ will not be economic. However, FL proposes that it will be economic up to the degree of 0.7 (Fig. 3b).

Therefore, fuzzy reasoning is very close to reality and it will be better to use this system for solving reservoir problems such as prediction of shear velocity form well log data

\subsection{Neuro-fuzzy}

In recent years, considerable attention has been devoted to the use of hybrid neural network and fuzzy logic techniques. It has been shown that neural network models can be used to construct internal models that recognize fuzzy rules. Neuro-fuzzy modeling is a technique for describing the behavior of a system using fuzzy inference rules within a neural network structure (Nikravesh and Aminzadeh, 2003).

Fig. 4 shows a NF system using the following fuzzy rules (Kamali \& Mirshady, 2005)

Rule 1: If $\mathrm{x} 1$ is $\mathrm{A} 1$ and $\mathrm{x} 2$ is $\mathrm{B} 1$, then class is 1

Rule 2: If $\mathrm{x} 1$ is $\mathrm{A} 2$ and $\mathrm{x} 2$ is $\mathrm{B} 2$, then class is 2

Rule 3: If $\mathrm{x} 1$ is $\mathrm{A} 1$ and $\mathrm{x} 2$ is $\mathrm{B} 2$, then class is 1

Layer 3. Combination of firing strengths: If several fuzzy rules have the same consequence class, this layer combines their firing strengths. Usually, the maximum connective (or operator) is used. 
Layer 4. Fuzzy outputs: In this layer, the fuzzy values of the classes are available. The values describe how well the input of the system matches to the classes.

Layer 5. Defuzzification: If the crisp classification is needed, the bestmatching class for the input is chosen as output.

\subsection{Back-propagation neural network}

ANN is a recently new tool for solving complex problems in petroleum industry. A back propagation artificial neural network (BP-ANN) is a supervised training technique that sends the input values forward through the network then computes the difference between the calculated output and the corresponding desired output from the training dataset. This error is then propagated backward through the net and the weights are adjusted during a number of iterations. The training stops when the calculated output values best approximate the desired values (Bhatt and Helle, 1999).

The major application area for ANN in the petroleum industry is to predict various reservoir properties. This ultimately is used a decision tool for exploration and development of the oil and gas fields.

\section{Shear and compressional waves}

Body waves are categorized to compressional and shear waves. Shear or S-waves do not propagate through the fluids and associated with compressional waves can provide useful information for hydrocarbon reservoirs characterization. There are many factors that affect on seismic velocities which were shown in Table 1 . However investigations show that shear velocity is strongly controlled by compressional velocities, type of pore fluid, clay content, and bulk density of the rock (Rezaee, 2001).

There are many applications for S-waves in petrophysical, seismic and geomechanical studies. For example the ratio of $\mathrm{Vp}_{\mathrm{p}}$ to $\mathrm{Vs}$ can be used as an index to characterize important reservoir properties; some of them are listed below: 
- Lithology determination $\left(\mathrm{Vp} / \mathrm{V}_{\mathrm{s}}\right.$ differs by lithology type, in dolomite=1.9, limestone $=1.8$, shaly sand $=1.7$, and clean sand $=1.6$ ).

- Determining degree of consolidation (for example to predict sanding problem).

- Identifying pore fluid type

- Geophysical studies such as AVO and VSP

Compressional wave velocity is obtained directly from sonic transit time. But S-wave velocity is measured at the laboratory on core samples or by means of Dipole Shear Sonic Imager tool (DSI). Most wells (especially old wells), do not have DSI, as well as it will be expensive and time consuming to measure S-wave velocity on core samples. Recently new tools have been developed for this purpose. However, they are unconventional and expensive.

Empirical relationships are useful for this purpose but they have limitations and disadvantages that some of them are listed below:

- Although this case study is a sandstone reservoir, most of the empirical methods have been developed for clean sandstone reservoirs and are not efficient for all lithologies.

- All the available empirical models developed for Vs prediction are mathematical models, and their used petrophysical parameters are limited, so they miss the generalization capability (Eskandari, et al., 2004).

- It is necessary to use a model with its all hypothesizes. When a theory is used out of related all hypothesizes, it will not be reliable (Koesomadinata and Mc Mechan, 2001).

So, it will be efficient and useful to predict Vs utilizing fast and robust intelligent systems from well log data.

\section{Modeling and prediction of shear velocity}

4.1 Fuzzy logic: In this study, a Takagi-Sugeno fuzzy inference system (TSFIS) was applied to estimate S-wave velocity from petrophysical data using Matlab software. For this purpose, the intervals of wells Bay\#1 and 
Emperor\#1 which had both the shear velocity and well log data were chosen to construct TS-FIS model (Table 2). Five logs including compressional velocity (Vp), gamma ray (GR), deep laterolog resistivity (Rlld), formation density compensate (FDC) and neutron porosity (NPHI) were considered as inputs and Vs as output of TS-FIS. For the studied wells, Vs data had been measured utilizing DSI tool and Vp was calculated from sonic transit time data. The relationship between used input data and shear velocity in well Bay\#1 has been shown in Fig. 5. A comparison among provided crossplots in Fig. 5 shows that the best correlation exists between Vs and compressional velocity $(\mathrm{Vp})$

Input and output membership functions and their parameters were extracted by subtractive clustering method and using 0.5 for clustering radius. Input membership functions were shown in Fig. 6 and all of them are Gaussian type. Output membership functions are constant values. The generated TS-FIS is consist of four Gaussian membership functions for each of the inputs and outputs that entitled by low, moderate, high and very high captions.

These membership functions formulated well log data including Vp, GR, Rlld, FDC and NPHI to Vs using following fuzzy if-then rules (Figs. 7\&8):

1- If $\mathrm{Vp}$ is very high and GR is high and Rlld is Moderate and FDC is high and NPHI is moderate then Vs is very high.

2- If $\mathrm{Vp}$ is moderate and GR is low and Rlld is high and FDC is low and $\mathrm{NPHI}$ is low then $\mathrm{Vs}$ is moderate.

3- If $\mathrm{Vp}$ is high and GR is very high and Rlld is low and FDC is very high and NPHI is very high then Vs is high.

4- If $\mathrm{Vp}$ is low and GR is moderate and Rlld is very high and FDC is moderate and NPHI is high then Vs is low.

The well East_Spar\#4 AST1 was chosen as a pilot well of the field to evaluate the reliability of constructed fuzzy models. However in the East_Spar\#4 AST1 Vs data only exist for the Barrow Group and the Mardie Greensand. The hole condition for the Mardie Greensand is bad due to washout. Therefore, Barrow Group was used to evaluate TS fuzzy models. 
According to Fig. 9 the correlation coefficient between real and FL predicted Vs in this well is 0.946.

4.2 Neuro-fuzzy: In NF approach, an adaptive neuro-fuzzy inference system (ANFIS) was used to verify TS-FIS models. Three Gaussian membership functions for each of data were extracted by grid partitioning method and an error-back propagation algorithm was used to adjust their parameters. Fig. 10 shows ANFIS structure for formulating well log data include Vp form sonic log, GR, Rlld, FDC and NPHI to Vs (802 data points). After 25 training Epochs, 524 nodes and 243 rules were generated and MSE performance function was fixed in 0.001. As mentioned the Barrow Group has been used to test constructed NF model. The correlation coefficient between predicted and measured Vs values for the mentioned test well with 637 data points is 0.942 (Fig. 11).

4.3 Artificial neural network: In this section we used a three layered BPANN to verify fuzzy and neuro-fuzzy results. Similar to TS-FIS and ANFIS, five inputs including Vp, GR, Rlld, FDC and NPHI data from wells Bay\#1 and Emperor\#1 which had both the shear velocity and well log data were considered in first layer. Number of neurons in hidden layer are 7, and output layer includes one neuron for Vs data. Levenberg-Marquardt training function associated with MSE performance function was used to optimize weights and default bias values. Used transfer function from layer one to two is TANSIG and from layer two to layer three is PURELIN. After 20 epochs of training MSE performance function was set to 0.001 (Fig. 12). According to Fig. 13 the Vs predicted values for the test well East-Spar\#4 AST1 are similar to results of FL and NF, so ANN verifies their reliability.

\section{Conclusion}

The results of this study show that TS-FIS has been successful for prediction of Vs form petrophysical data including Vp from sonic log, GR, Rlld, FDC and NPHI respectively, in studied sandstone reservoir of 
Carnarvon basin. Also ANFIS and BP-ANN techniques confirm the reliability of fuzzy models. The MSE performance function was fixed in 0.001 for all of the constructed intelligent models and they are able to successful prediction of Vs for other wells of studied basin which has no Vs data. A Comparison between measured and predicted Vs versus depth shows a good agreement for the three techniques (Fig. 14). Measured error using MSE function is about 0.001 .

These techniques are easy, fast, and powerful tools for intelligent reservoir characterization and solving complicated problems which are difficult, time consuming and expensive. 


\section{References}

Bastos, A.C., Dillon, L.D., Vasquez, G.F., and Soares, J.A., 1998. Core-derived acoustic, porosity and permeability correlation for computation pseudo-logs. Geological Society London, Special Publications., 136:141-146.

Bhatt, A., Helle. H. B., 1999. Porosity, permeability and TOC prediction from well logs using a neural network approach. 61 ST EAGE, Conf. Helsinki, Finland, pp. 1-4.

Castagna, J.P., Batzle, M.L. and Eastwood, R.L., 1985. Relationship between compresional and shear wave velocities in silicate rocks. Geophysics., 50: 571-581.

Castagna, J.P., and Batzle, M. L., and Kan, T.K., 1993. Rock Physics - The link between rock properties and AVO response, in Castagna, J.P., and Backus, M.M., Eds., Offset -dependent reflectivity -Theory and practice of AVO analysis: Soc. Expl. Geophysics., 124-157.

Chiu, S., 1994. Fuzzy model identification based on cluster estimation. Journal of Intelligent \& Fuzzy systems., 2: 267-278.

Domenico, S.N., 1984, Rock lithology and porosity determination from shear and compressional velocity. Geophysics., 49: 1188-1195.

Eskandari, H., Rezaee, M.R., and Mohammadnia, M., 2004. Application of Multiple Regression and Artificial Neural Network Techniques to Predict Shear Wave Velocity from well Log Data for a Carbonate Reservoir, SouthWest Iran. CSEG RECORDER, 42-48.

Gassmann, F., 1951. Uber die Elastizität poröser medien: Vieteljarsschrift der Naturforschenden Ges. Zurich., 96: 1-23.

Greenberg, M.L., and castagna, J.P., 1992. Shear wave velocity estimation in porous rocks: Theoretical formulation, prelimining verification and applications. Geophysical prospecting., 40: 195-209.

Han, D., 1989. Empirical relationships among seismic velocity, effective pressure, porosity and clay content in sandstone. Geophysics., 54: 82-89. 
Kamali, M.R., and Mirshady, A. A., 2004. Total Organic Carbon Content Determined from Well Logs Using $\Delta \operatorname{LogR}$ and Neuro Fuzzy Techniques., Journal of Petroleum Science and Engineering., 45: 141-148.

Koesoemadinata, A.P., and Mcmechan, G.A., 2001. Empirical estimation of viscoelastic seismic parameters from petrophysical properties of sandstone. Geophysics., 66: 1457-1470.

Kosko, B, 1991. Fuzzy Thinking. Hyperion, New York.

Krief, M., Garat, J., Stellingwerf, J., and Venter, J., 1990 . A petrophysical interpretation using the velocities of $\mathrm{P}$ and $\mathrm{S}$ waves(full wave from sonic). The Log Analysit., 31: 35-369.

Mamdani, E. H., Assilian. S, 1975. An experimental in linguistic synthesis with a fuzzy logic control: International journal Man-Machine studies., 7: 1-13.

Matlab user's guide, 2001, Fuzzy logic Toolbox, Matlab CD-Room, 2001. By the math works, Inc.

Murphy, W., Reischer, A., and Hsu, K., 1993. Modulus decomposition of compressional and shear velocities in sand bodies. Geophysics., 58: 227239 .

Nikravesh, M., and Aminzadeh, F., 2003. Soft Computing and Intelligent Data Analysis in Oil Exploration, Part1: Introduction: Fundamentals of Soft Computing. 744p. Elsevier, Berkeley, UAS.

Pickett, G.R., 1963. Acoustic character logs and their application in formation evaluation. Journal of Petroleum Technology., 15: 650-667.

Rezaee, M. R., 2001. Petroleum Geology. 410p, Alavi Publications, Tehran, Iran.

Sugeno, M., 1985. Industrial applications of fuzzy control. Elsevier Science, Amsterdam.

Takagi, T., Sugeno. M., 1985. Identification of Systems and its Application to modeling and Control. Institute of electrical and electronics engineers transactions on systems, Man and Cybemetics., 15: 116-132.

Wang, Z., 2001. Fundamentals of seismic rock physics. Geophysics., 66: 398412. 
Yagar, R. R., Zadeh. L. A., 1992. An introduction to fuzzy logic applications in intelligent systems. Kluwer Academic Publishers., 165: 69-70.

\section{Tables}


Table 1. Three main factors control on seismic velocities (Wang, 2001).

\begin{tabular}{|l|l|l|}
\hline \multicolumn{1}{|c|}{ Environment } & \multicolumn{1}{|c|}{ Fluid } & \multicolumn{1}{c|}{ Rock } \\
\hline Reservoir Pressure & Saturation & Pore Shape \\
Geometry of Layer & Gas to Oil Ratio & Porosity \\
Production History & Fluid Type & Fracturing \\
Reservoir Processes & Hydrophilic & Isotropy \\
Temperature & Fluid phase & Clay Content \\
Stress History & Viscosity & Bulk Density \\
Frequency & & Texture \\
& & Cementation \\
& & Lithificatioin History \\
& & Compaction \\
\hline
\end{tabular}

Table 2. Wells and intervals that have shear velocity (Vs) data in the studied area.

\begin{tabular}{cccc}
\hline \hline \multirow{3}{*}{ Well } & Formation & Tops & \\
& MDRT & Lithology & Vs \\
& (m) & & \\
\hline
\end{tabular}




\begin{tabular}{|c|c|c|c|c|}
\hline \multirow[t]{13}{*}{ BAY-1 } & Sealevel & 27.84 & & \\
\hline & Seabed & 57.0 & & \\
\hline & Toolonga Calcilutite & $?$ & Calcareous claystone & \\
\hline & Gearle Siltstone & 827.0 & Silty claystone & \\
\hline & Windalia Radiolarite & 982.0 & Interbedded siltstone, claystone & \\
\hline & Windalia Sand & 1554.0 & & \\
\hline & Muderong Shale & 1610.0 & Massive claystone & \\
\hline & Mardie Greensand & 1633.0 & Glauconitic siltstone, claystone & \\
\hline & Barrow Group & 1788.0 & $\begin{array}{l}\text { Interbedded sandstone, siltstone, } \\
\text { claystone }\end{array}$ & $\checkmark$ \\
\hline & Dupuy Formation & 1809.0 & $\begin{array}{l}\text { Claystone, arg. sandstone, } \\
\text { siltstone }\end{array}$ & $\checkmark$ \\
\hline & Bay Sandstone & 3255.0 & $\begin{array}{l}\text { sandstone, argillaceous } \\
\text { sandstone }\end{array}$ & $\checkmark$ \\
\hline & Dingo Shale & 3537.5 & Claystone & $\checkmark$ \\
\hline & Total Depth & 3710.0 & & $\checkmark$ \\
\hline \multirow{12}{*}{ Emperor-1 } & Sealevel & 27.70 & & \\
\hline & Seabed & 45.50 & & \\
\hline & Toolonga Calcilutite & 474.0 & & \\
\hline & Gearle Siltstone & 734.0 & Claystone & \\
\hline & Windalia Radiolarite & 1290.0 & Claystone & \\
\hline & Windalia Sand & 1352.0 & Claystone & \\
\hline & Muderong Shale & 1406.0 & Claystone & \\
\hline & Mardie Greensand & 1504.5 & $\begin{array}{l}\text { claystone/glauconitic siltstone } \\
\text { and sandstone }\end{array}$ & \\
\hline & Barrow Group & 1530.5 & $\begin{array}{l}\text { Sandstone, claystone, } \\
\text { argillaceous sandstone }\end{array}$ & $\checkmark$ \\
\hline & Top Foresets & 1748.0 & $\begin{array}{l}\text { dominantly argillaceous } \\
\text { sandstone }\end{array}$ & $\checkmark$ \\
\hline & Primary Objective & 2209.0 & $\begin{array}{l}\text { Sandstone, argillaceous } \\
\text { sandstone }\end{array}$ & $\checkmark$ \\
\hline & Total Depth & 2360.0 & & $\checkmark$ \\
\hline \multirow{10}{*}{$\begin{array}{l}\text { East Spar } \\
\text { 4AST1 }\end{array}$} & Sealevel & 123.0 & & \\
\hline & Undifferentiated & 123.0 & $\begin{array}{l}\text { Calcarenite, sandstone, } \\
\text { Claystone }\end{array}$ & \\
\hline & Withnell Formation & 1318.0 & $\begin{array}{l}\text { Calcareous Claystone and } \\
\text { siltstone }\end{array}$ & \\
\hline & Toolonga Calcilutite & 1344.0 & $\begin{array}{l}\text { Calcareous Claystone and } \\
\text { siltstone }\end{array}$ & \\
\hline & Gearle Siltstone & 1749.0 & Claystone & \\
\hline & Windalia Radiolarite & 2226.0 & Claystone & \\
\hline & Muderong Shale & 2244.0 & Claystone & \\
\hline & Mardie Greensand & 2507.0 & Greensand and siltstone & $\checkmark$ \\
\hline & Barrow Group & 2520.1 & Sandstone, siltstone & $\checkmark$ \\
\hline & Total Depth & 2750.0 & & $\checkmark$ \\
\hline
\end{tabular}

\section{Figures captions}

Fig. 1 - Membership functions for a crisp set $C$ and a fuzzy set $F$. 
Fig. 2 - A comparison of "and", "or" and "not" operators in FL (multi-valued logic) and CL (two-valued logic) approaches.

Fig. 3 - Membership functions for porosity cutoff in CL (a) and FL (b) approaches.

Fig. 4 - Schematic structure of a neuro-fuzzy system (From (Kamali \& Mirshady, 2005)

Fig. 5 - Crossplots between petrophysical data including NPHI(a), Vp(b), GR(c), FDC(d), Rlld(e) versus shear velocity. According to these crossplots, Vp has stronger relationship with Vs.

Fig. 6 - Extracted membership functions using subtractive clustering (cluster radius $=0.5$ ) for Vp (a), GR (b), Rlld (c), FDC (d), NPHI (e).

Fig. 7 - Formulation between well log data (inputs) to Vs (output) using the TSFIS.

Fig. 8 - ANFIS structure for formulating well log data to shear wave velocity.

Fig. 9 - Crossplot showing correlation coefficient between measured and predicted Vs using FL for the test well East Spar\#4 AST1.

Fig. 10 - Schematic diagram of constructed model based on FL for predicting Vs from petrophysical data.

Fig. 11 - Crossplot showing correlation coefficient between measured and predicted Vs using NF for the test well East Spar\#4 AST1.

Fig. 12 - Graph of Mean Squared Error (MSE) versus training epochs for training (blue), validation (green) and test data (red).

Fig. 13 - Crossplot showing correlation coefficient between measured and predicted Vs using ANN for the test well East Spar\#4 AST1.

Figure 14 - A comparison between measured and predicted Vs using FL(a), $\mathrm{NF}(\mathrm{b})$ and $\mathrm{ANN}(\mathrm{c})$ for the test well East Spar\#4 AST1. Real values were shown by solid lines and predicted values by points.

Figures 


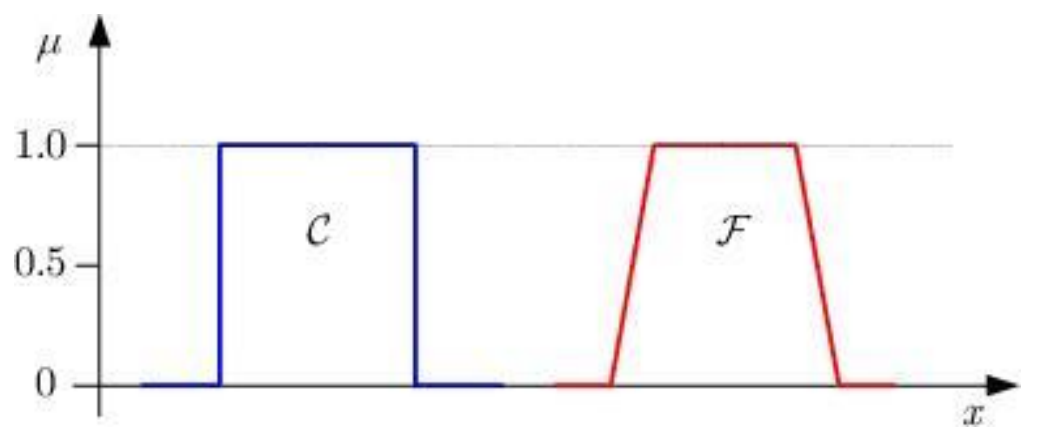

Fig. 1 

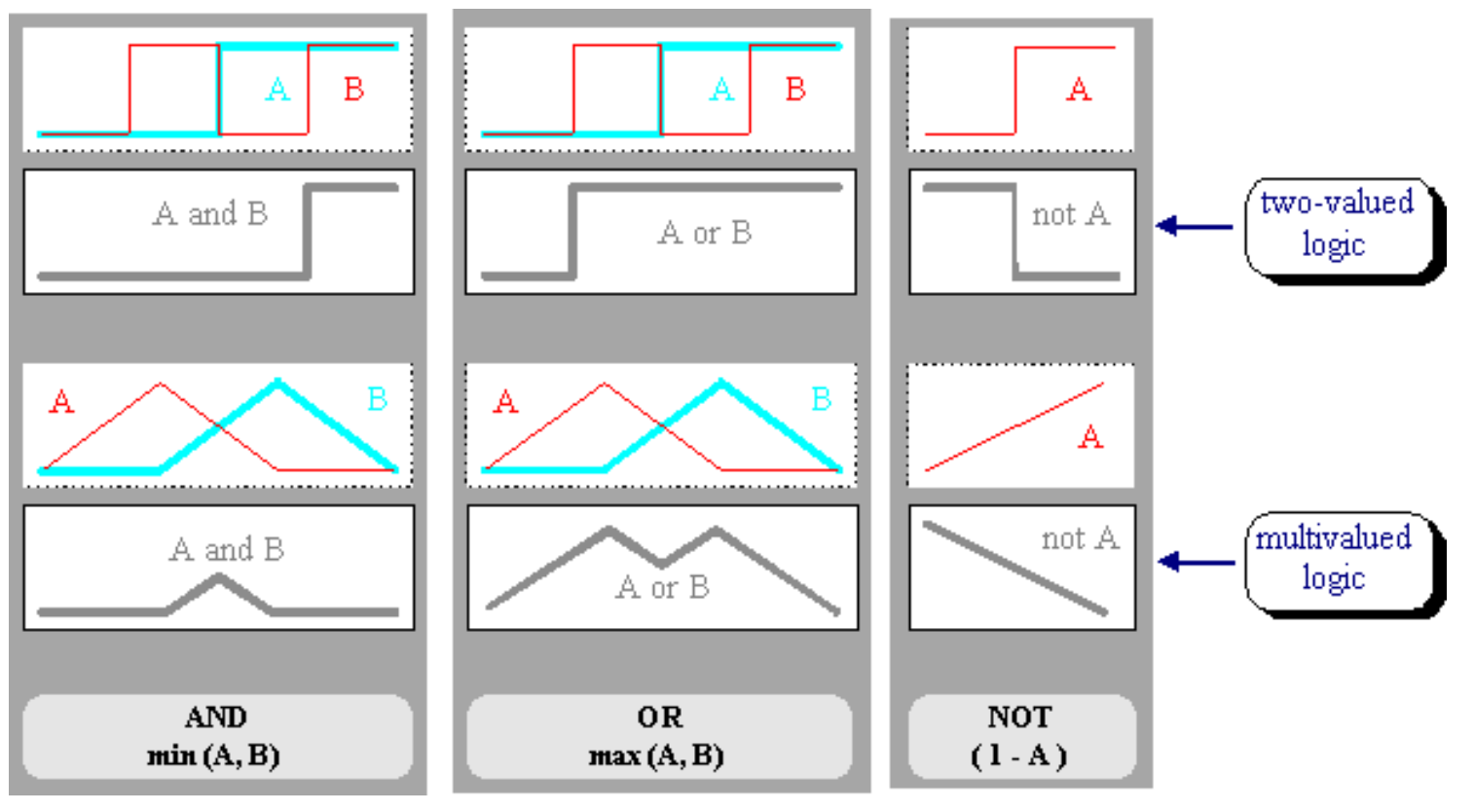

Fig. 2 

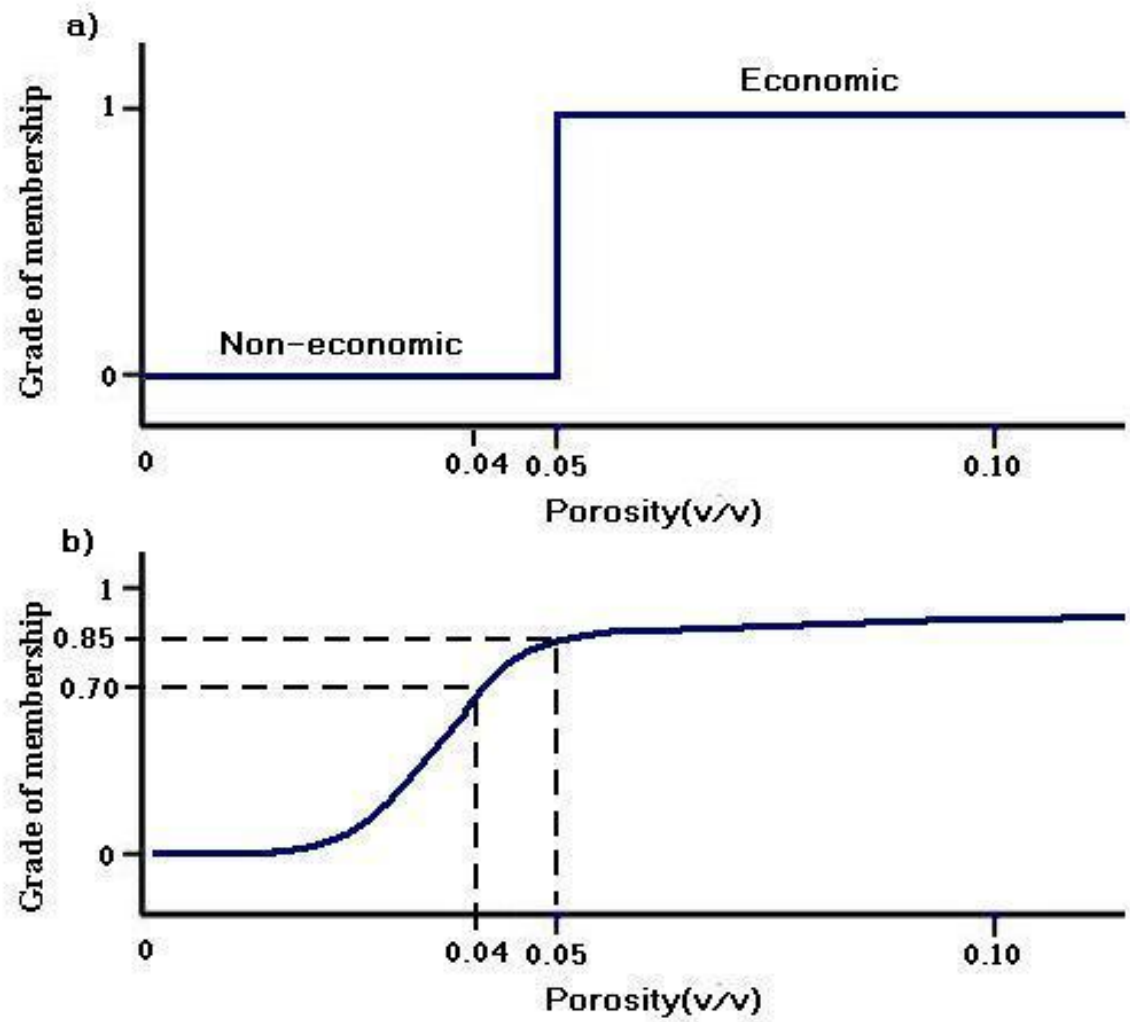

Fig.3 


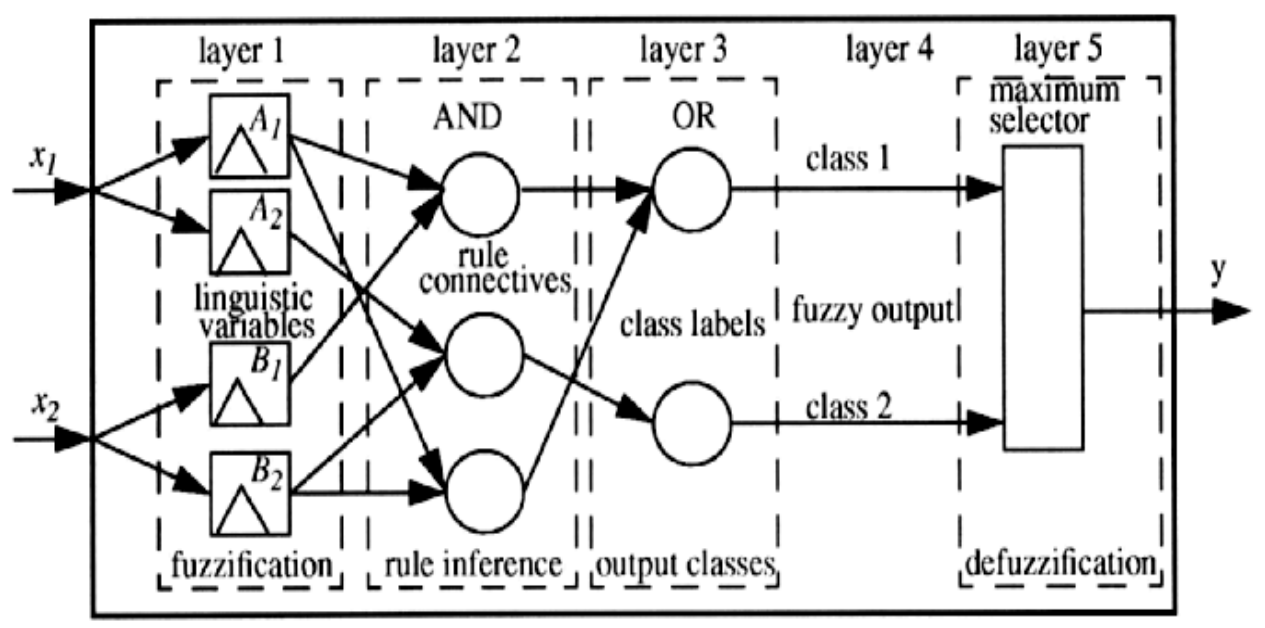

Fig. 4
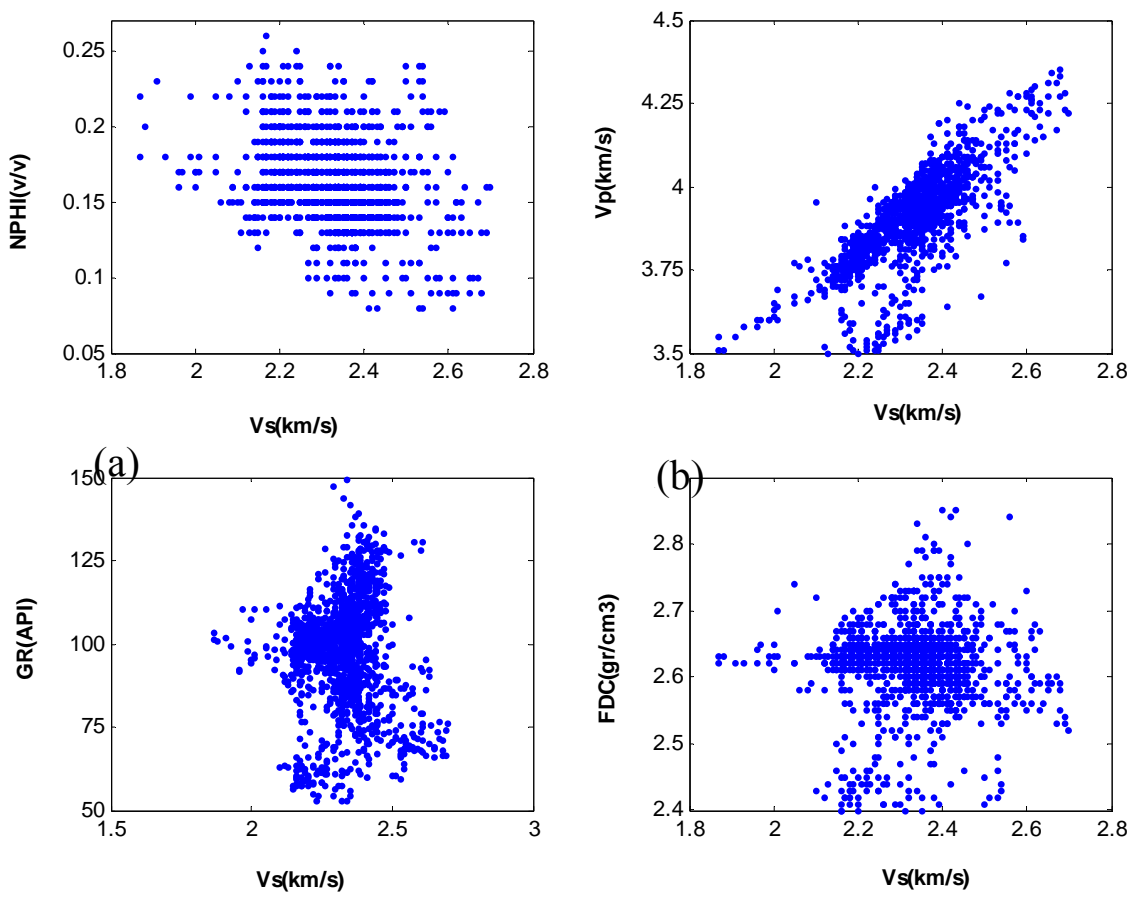
(c)

(d)

(e)

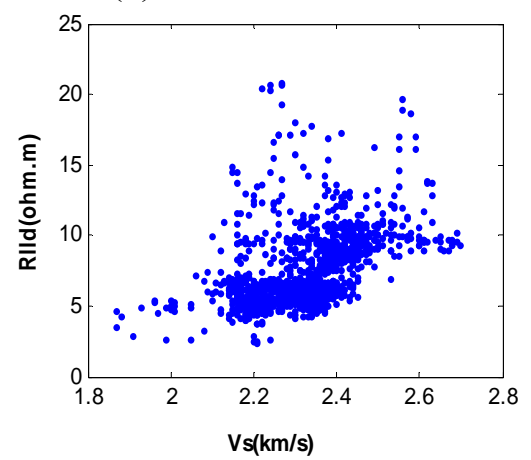

Fig. 5 

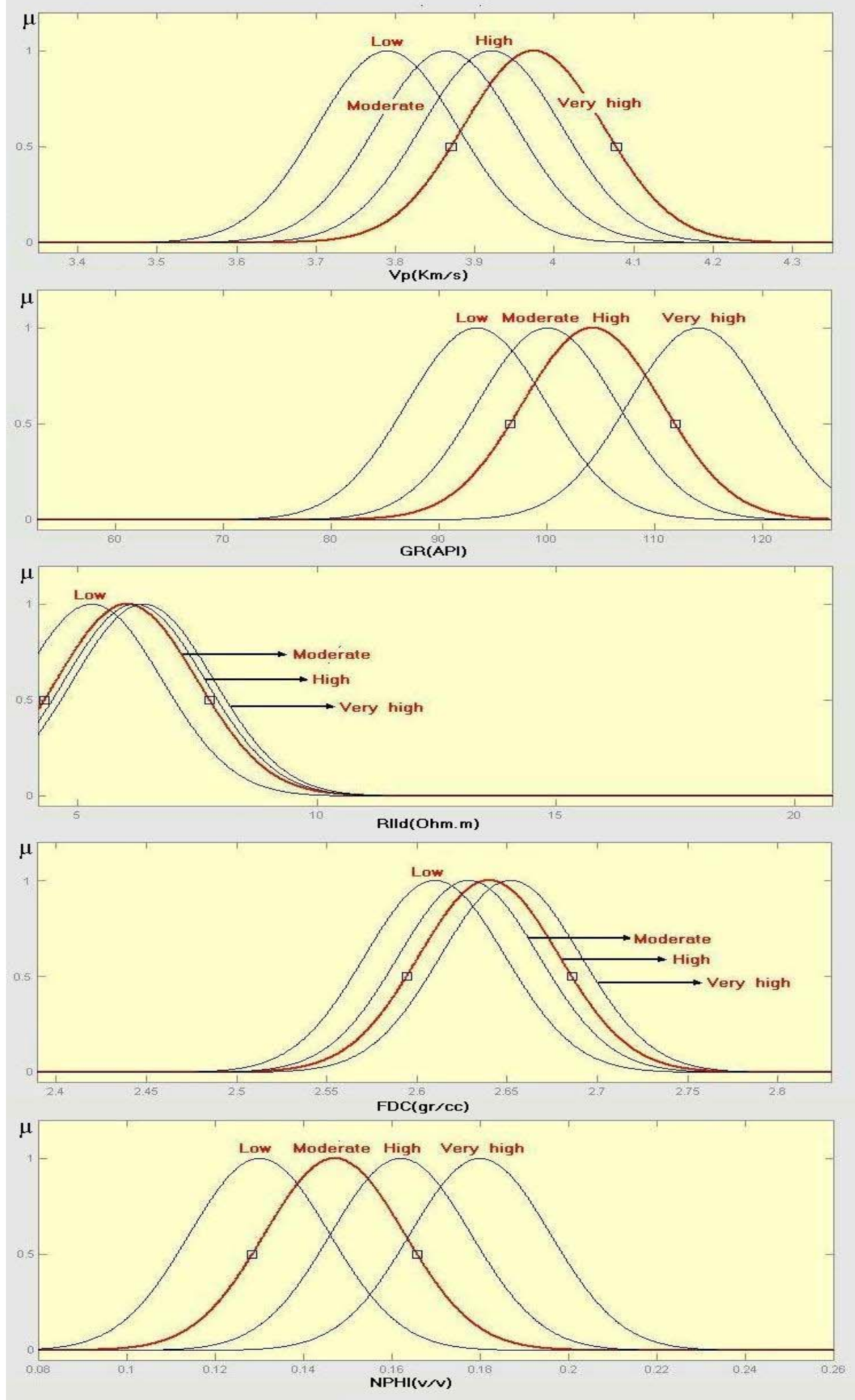

Fig. 6 


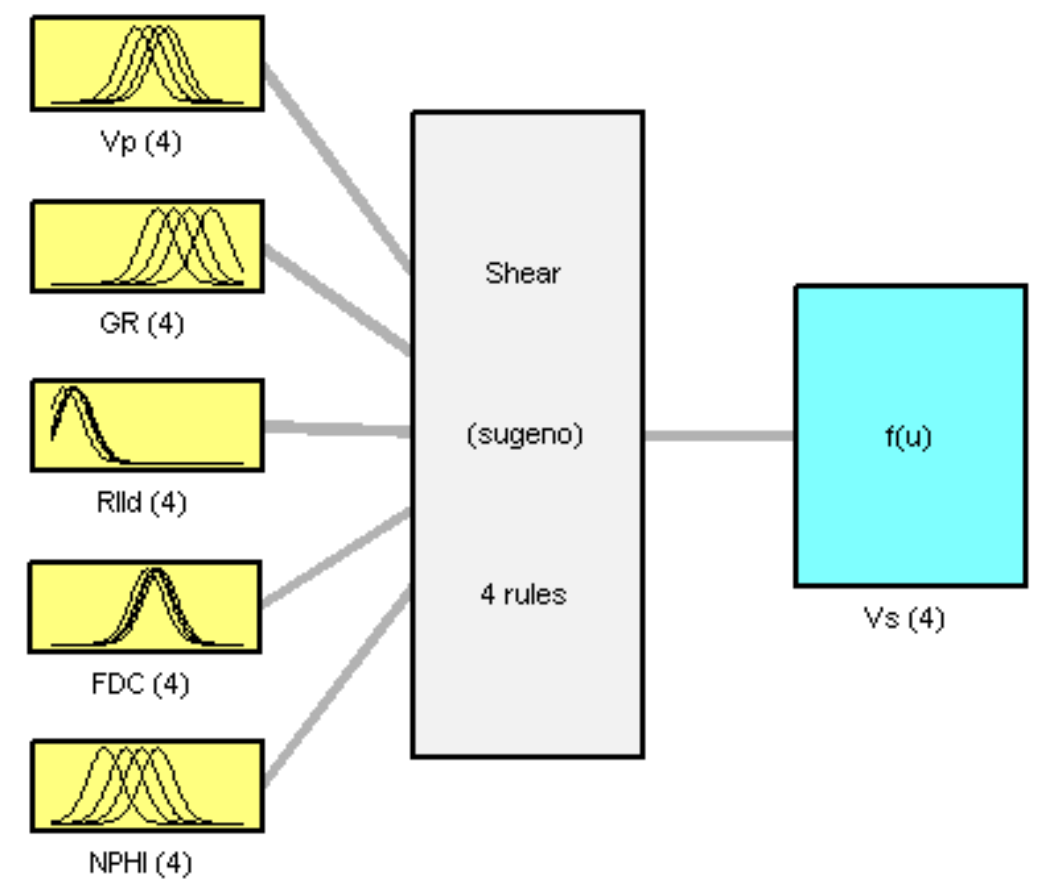

Fig. 7 


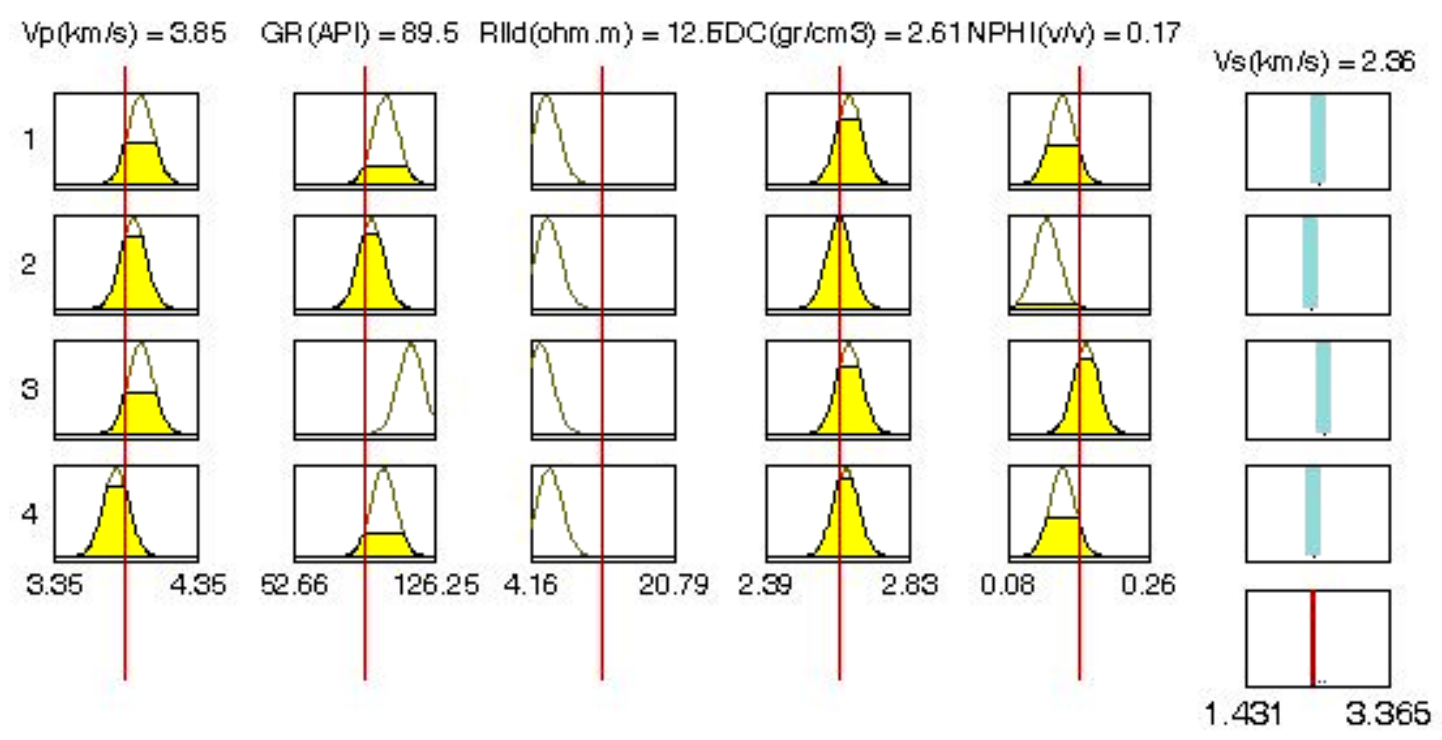

Fig. 8 


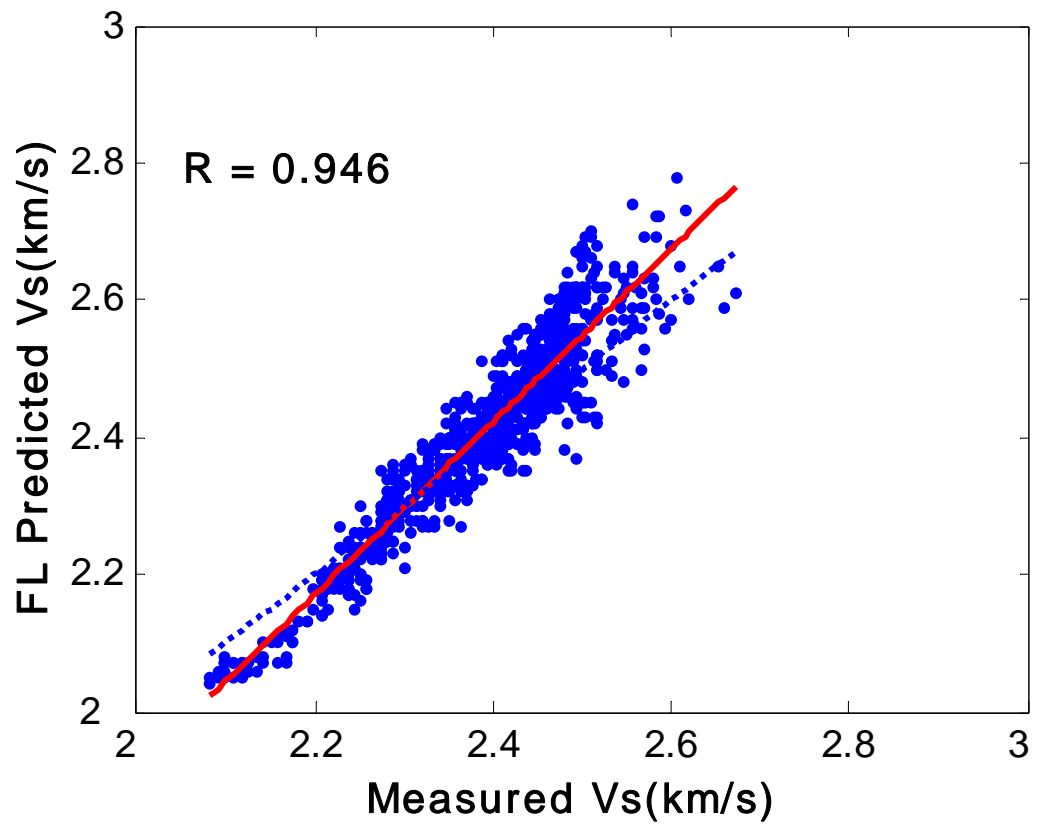

Fig 9 


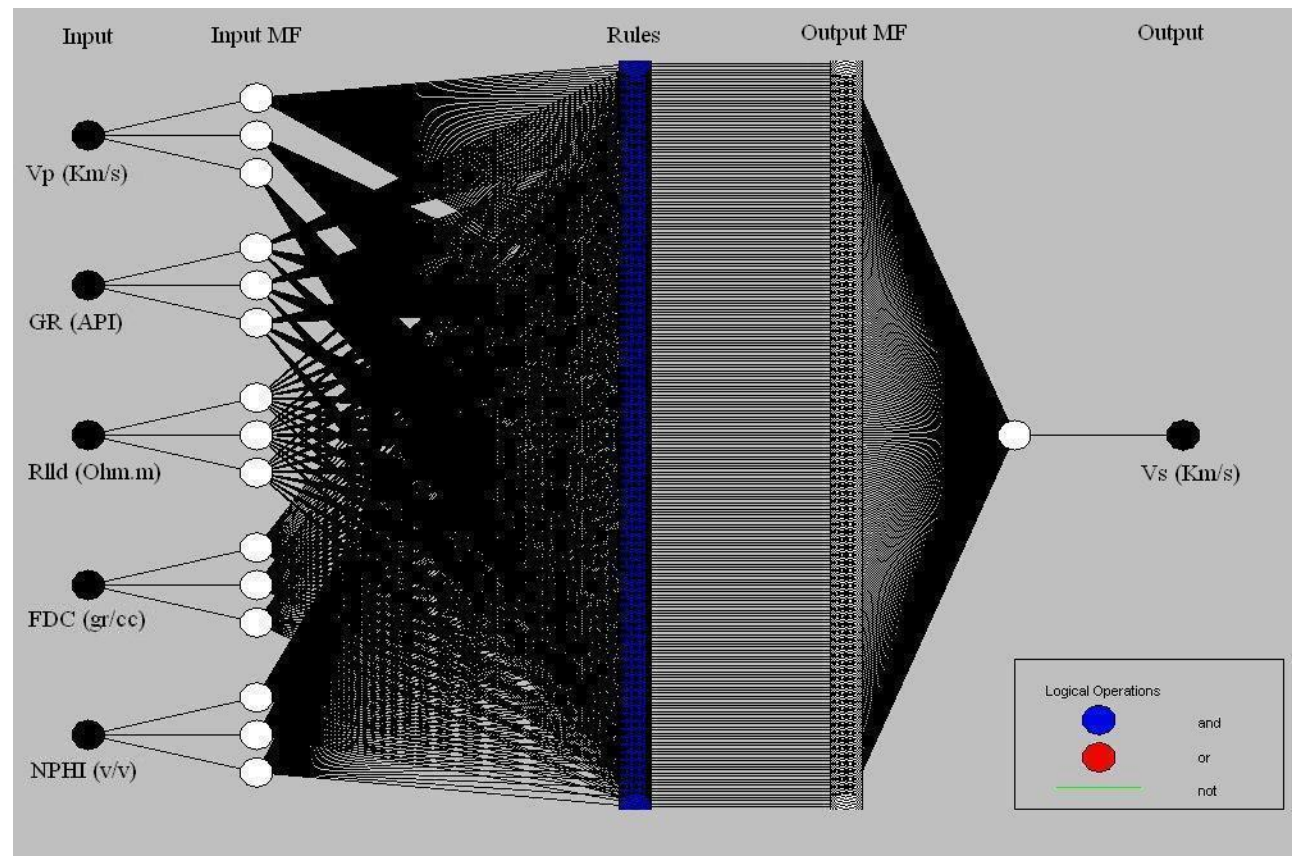

Fig. 10 


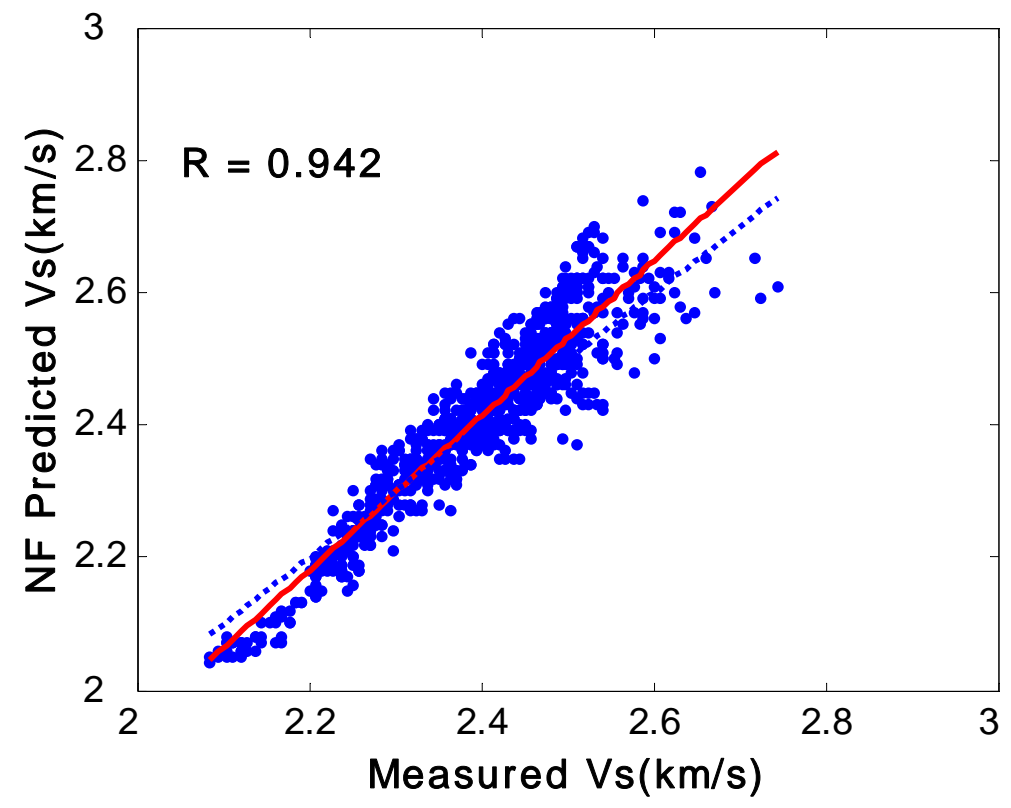

Fig. 11 


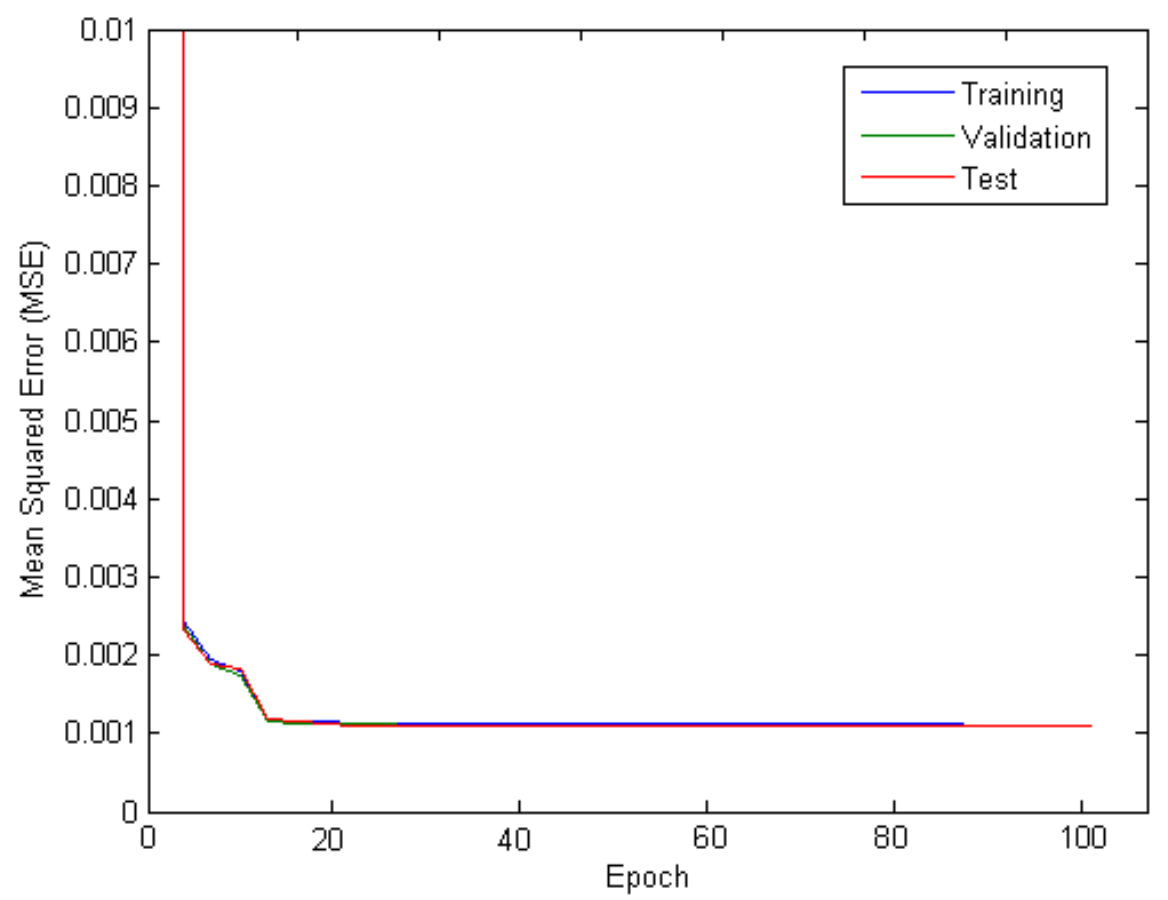

Fig. 12 


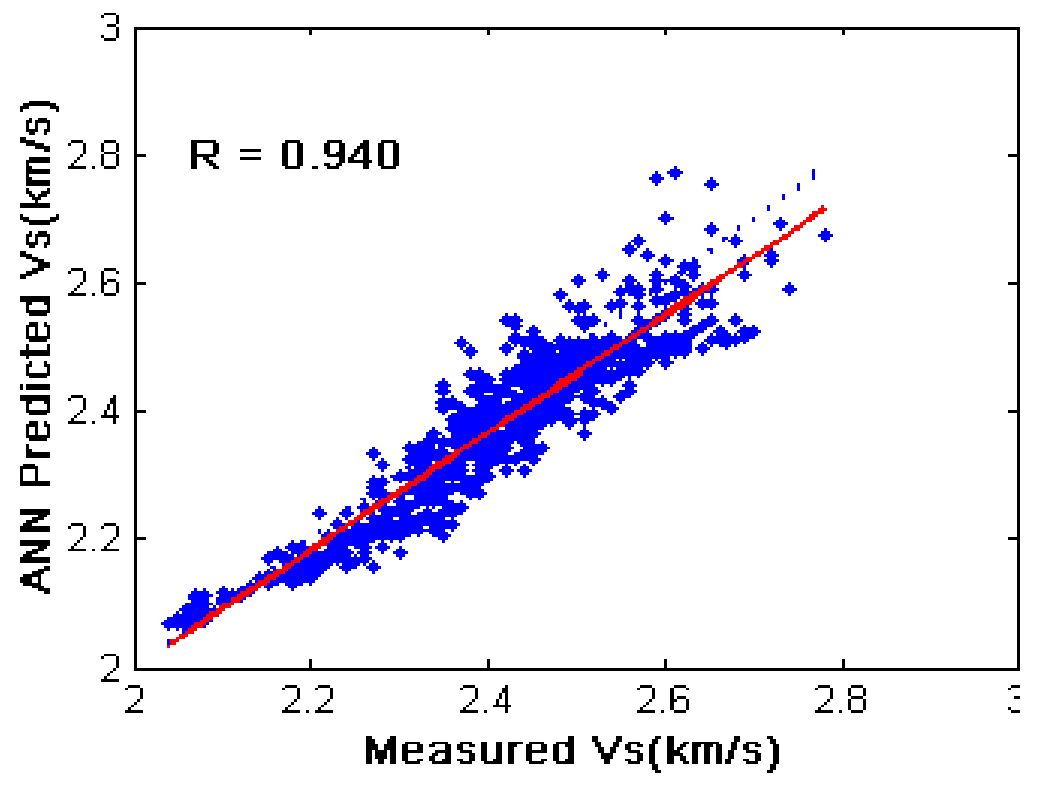

Fig. 13 
(a)

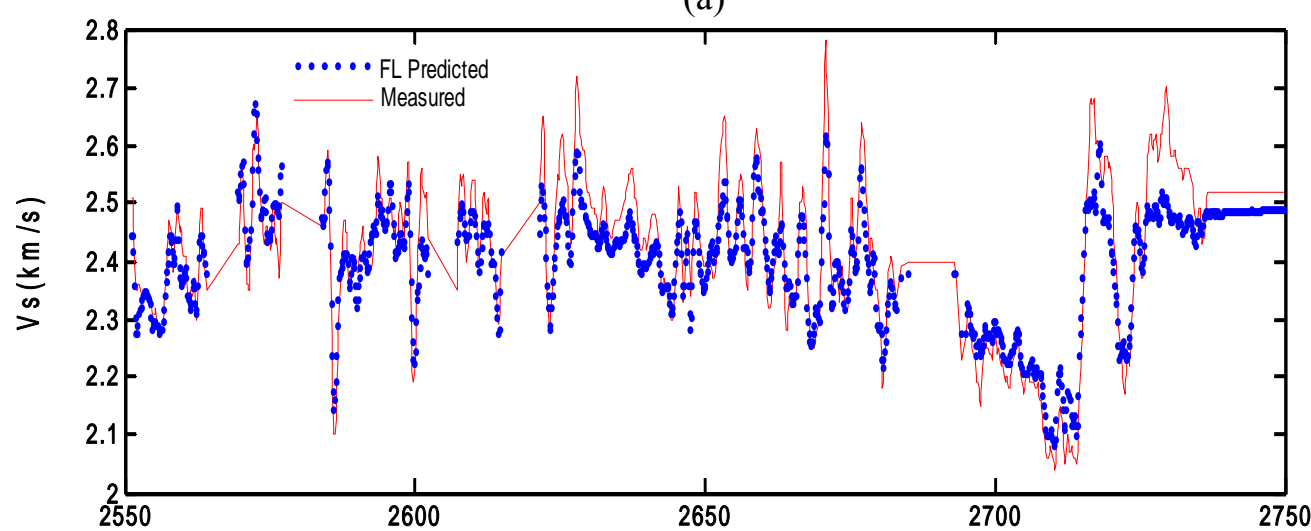

(b)

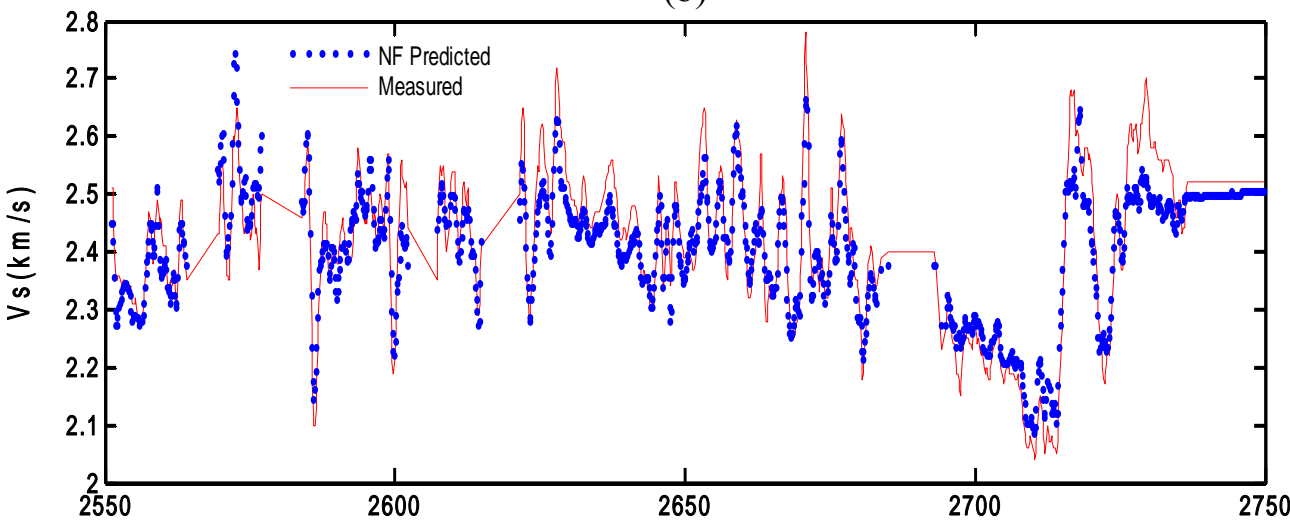

(c)

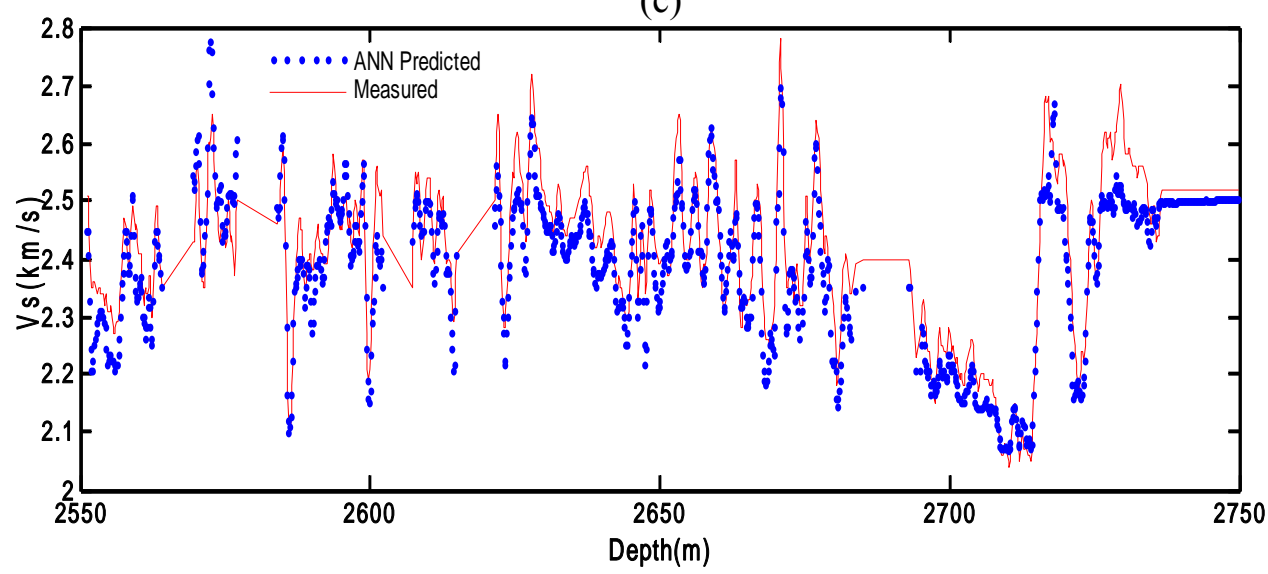

Fig. 14 